\title{
Effect on breast cancer screening response in The Netherlands of inviting women for an additional scientific investigation
}

\author{
P H M Peeters, C G M M Beckers, J M W Hogervorst, H J A Collette
}

\begin{abstract}
Study objective - The study aimed to determine whether asking women to undertake an additional scientific study would deter them from attending screening for breast cancer.

Design - A randomised study was conducted in all women aged 50-70 years who were eligible for breast cancer screening and living in the city of Utrecht. A total of 1863 women were invited for mammography only and 1863 women were invited to participate in the European Prospective Investigation into Cancer and Nutrition (EPIC) in addition to the mammography.

Subjects - The study population comprised a random sample of $3726,15 \%$ of the female population of Utrecht aged 50-70 years.

Main results - The attendance rate for breast cancer screening was $53 \%$, irrespective of the invitation to participate in the additional scientific study.

Conclusions - Asking women to attend for an investigation in addition to the routine screening procedure for breast cancer did not affect the overall response to screening.
\end{abstract}

(f Epidemiol Community Health 1994;48:175-177)

In several European countries screening for breast cancer in women aged 50 years and over is routine. In The Netherlands two breast cancer screening projects have been operating since the mid 1970s. ${ }^{12}$ They both used mammography at regular intervals. A reduction in mortality from breast cancer as a result of screening was detected at the beginning of the $1980 \mathrm{~s}$ in these and other projects. ${ }^{3-7}$ As a consequence screening for breast cancer became widespread in The Netherlands for women aged over 50 . A high participation rate for screening is of the utmost importance if benefits are to be achieved in a population. ${ }^{8}$ In general, older people tend to be more reluctant to participate than younger people, and participation rates may drop as screening becomes routine. ${ }^{9}$

To maintain as high a screening response rate as possible, women in The Netherlands are invited personally to attend for screening, and an appointment date is mentioned in the invitation letter. The location is planned to be within a distance of eight to 12 kilometres and the examination takes place in a special screening unit, preferably not attached to a hospital but rather to a local public community unit. In this way participation rates of $60-80 \%$ can be achieved in women over age $50 .^{19}$

Because screening programmes started in 1974 as scientific research projects, they were managed by researchers and medical doctors (for example, radiologists, epidemiologists, pathologists). Currently, however, screening has to be nationwide and very high numbers of women need to be invited. The screening units have their own organisational structures headed by managers. There is no time or money left for additional scientific research as there was in the early years of screening.

However, these screening organisations are still a perfect base for including prospective epidemiological studies, for several reasons. Firstly, screening centres (in The Netherlands) receive an updated database of names and addresses of the older female population in a defined area from the municipal administration. Secondly, participants can be contacted directly as they come to the unit for mammography. Another advantage is the opportunity to follow up the participants as they are invited (in The Netherlands) for a screening examination every two years. Furthermore, women are often under-represented in scientific studies - most of which are restricted to younger men. With the aging of the population, however, the health of women becomes even more important and should be studied more frequently. ${ }^{10}$

Against these advantages is the possible risk of deterring women from screening if they have to attend for additional scientific investigations. The present study evaluates this hazard. Women routinely invited for breast screening were also invited to participate in the European Prospective Investigation into Cancer and Nutrition (EPIC). This study is conducted in seven European countries, and is coordinated by the International Agency for Research on Cancer (IARC), Lyon, France. ${ }^{11}$ Preparations for EPIC were made in 1988-92, and the actual enrolment of 50000 healthy people in each participating country started in 1992-93. The Netherlands is one of the participating countries and here two institutes are involved in collecting data for EPIC - the University of Utrecht and the National Institute of Public Health and Environmental Protection.

A feasibility study, the "prospect study," was carried out by the University of Utrecht. This study, which preceded EPIC, was associated with the breast cancer screening unit. Participation rates for screening were evaluated. 
Table 1 Distribution of age, marital status, nationality, and urban district of Utrecht in the control and the prospect study groups

\begin{tabular}{lcc}
\hline & $\begin{array}{c}\text { Prospect study group } \\
(n=1863)(\%)\end{array}$ & $\begin{array}{l}\text { Control group } \\
(n=1863)(\%)\end{array}$ \\
\hline Age (y): & $339(18)$ & $338(18)$ \\
$50-54$ & $494(27)$ & $489(26)$ \\
$55-59$ & $311(17)$ & $327(18)$ \\
$60-64$ & $528(28)$ & $525(28)$ \\
$65-69$ & $191(10)$ & $184(10)$ \\
>69 & $1731(93)$ & $1729(93)$ \\
Married: & $132(7)$ & $134(7)$ \\
Ever & & $1773(95)$ \\
Never & $1779(95)$ & $90(5)$ \\
Nationality: & $84(5)$ & $236(13)$ \\
Dutch & & $166(9)$ \\
Other & $245(13)$ & $732(39)$ \\
District: & $167(9)$ & $707(38)$ \\
South east & $727(39)$ & \\
East & $703(38)$ & \\
North east & North &
\end{tabular}

* Details on 21 women in the prospect study group and 22 women in the control group missing.

\section{Methods}

Participation rates for breast cancer screening were evaluated in a randomised controlled study. A random sample of 3726 women was selected from the total female population of the city of Utrecht aged 50-70 years $(n=24600)$. They were randomly divided into two groups: 1863 women received their usual invitation for routine mammography (control group) and the remainder (prospect study group) were invited for the usual screening and for the additional procedures necessary for the EPIC study. For reasons of privacy the names and addresses of the women invited for the prospect study were not passed to the investigators. Women were informed about the prospect study by means of a letter from the management of the screening centre sent out two to three weeks before the usual invitation for screening. This letter explained why the management of the screening unit wanted to draw the woman's attention to the prospect study. A letter from the researchers and information about the prospect study were also included. If a woman wanted to participate in the prospect study, she had to return a reply coupon to the screening unit, and her name was then passed to the investigators of the prospect study. Women willing to participate were then sent two questionnaires and were asked to fill them out at home and to bring them back if they were coming for a screening examination. The questionnaires included questions on their usual diet and other lifestyle habits (for example, use of alcohol and drugs, smoking, reproductive history, physical activity, and medical history). After the mammogra-

Table 2 Screening attendance in the control and the prospect study group in relation to age

\begin{tabular}{|c|c|c|c|c|c|}
\hline \multirow[b]{2}{*}{ Age (y) } & \multicolumn{3}{|c|}{ Prospect study group ( $n=1863)$} & \multicolumn{2}{|c|}{ Control group $(n=1863)$} \\
\hline & $\begin{array}{l}\text { Invited for } \\
\text { screening and the } \\
\text { prospect study }\end{array}$ & $\begin{array}{l}\text { Attended for } \\
\text { screening } \\
(\%)\end{array}$ & $\begin{array}{l}\text { Attended the } \\
\text { prospect study } \\
(\%)\end{array}$ & $\begin{array}{l}\text { Invited for } \\
\text { screening }\end{array}$ & $\begin{array}{l}\text { Attended for } \\
\text { screening } \\
(\%)\end{array}$ \\
\hline $\begin{array}{l}50-54 \\
55-59 \\
60-64 \\
65-69 \\
>69 \\
\text { Total }\end{array}$ & $\begin{array}{r}339 \\
494 \\
311 \\
528 \\
191 \\
1863\end{array}$ & $\begin{array}{r}199(59) \\
285(58) \\
168(54) \\
276(52) \\
56(29) \\
984(53)\end{array}$ & $\begin{array}{c}121(36) \\
175^{*}(35) \\
108^{*}(35) \\
147^{*}(28) \\
26^{*}(14) \\
577^{(31)}\end{array}$ & $\begin{array}{r}338 \\
489 \\
327 \\
525 \\
184 \\
1863\end{array}$ & $\begin{array}{r}186(55) \\
298(61) \\
162(50) \\
259(49) \\
75(41) \\
980(53)\end{array}$ \\
\hline
\end{tabular}

* Including $2,3,1$, and 2 women respectively who came for the prospect study only (withou screening). phy, women were directed to a prospect study "interviewer" in the same building. There, measurements of blood pressure (twice), height, weight, and circumferences of waist and hips were taken, after an informed consent paper had been signed. In addition, a blood sample was collected and stored at minus $196^{\circ} \mathrm{C}$. The total prospect study procedure lasted on average 30 to 60 minutes in addition to the screening examination. At home, it took women at least one hour to fill in the questionnaires.

Screening participation rates were calculated for the control and the prospect study groups, according to age. Participation rates refer to attendance after a first invitation. Women who did not attend after a first call were routinely invited a second time. Because of the limited duration of the prospect study (March-July 1992), the evaluation of attendance rates stopped at the end of September 1992.

\section{Results}

COMPARABILITY OF THE CONTROL AND

PROSPECT STUDY GROUPS

Table 1 gives an overview of the distribution of age, marital status, nationality, and district of residence. All these parameters are known predictors of screening attendance. As expected because of randomisation, the variables associated with the screening response were distributed equally in the control and the prospect study groups.

PARTICIPATION IN THE PROSPECT STUDY Of the total of 1863 women invited for the screening and to participate in the prospect study, 666 women responded positively, 433 sent back their reply coupon saying that they did not want to participate in the prospect study, and 764 did not respond at all. Of the 666 women willing to participate in the study, 89 were not included because of illness, problems with the Dutch language, or because of planned holidays.

\section{PARTICIPATION FOR SCREENING}

Screening attendance rates in the control and the prospect study groups are shown in table 2 . The attendance rate for breast cancer screening in women who were also invited to participate in the prospect study was $53 \%$. The rate in the control group was the same. Age specific attendance rates were similar in both groups, with the exception of women aged over 69 . In the control group the response rate to screening was $41 \%$ and the rate in the prospect group was $29 \%$ - a statistically significant difference $\left(\chi^{2}=5.4 ; \mathrm{p}<0.05\right)$

Of all women invited for the screening examination and the prospect study $(n=1863), 415$ attended for breast cancer screening only, 569 women attended for a mammography and participated in the prospect study, and eight women attended the prospect study only. These eight women all mentioned that they had not attended for screening because they were already under the surveillance of a hospital doctor. 


\section{Discussion}

As screening for breast cancer becomes widespread in western countries, regional units become suitable for prospective epidemiological studies. Attaching research to these units must not influence participation rates, however, since as high rates for screening as possible are necessary to reduce breast cancer mortality maximally in the screened population.

This study shows that inviting women for scientific research in addition to a screening examination did not deter them from attending screening. The participation rate for screening in the study group was $53 \%$, equal to the rate in a comparable control group. There was, however, a difference in attendance in women aged over 69 years. This was almost half in the study group compared with the rate in the control group. Perhaps for older women additional investigations become too much a burden. In The Netherlands it was decided not to continue inviting women over age 69 years for regular breast cancer screening examinations. ${ }^{12}$ In addition, for the EPIC study it was decided not to include women aged over 69 because of the prospective design of the study.

It is possible that the attendance rate will fall in this prospect study group if they are invited again for screening in two years' time (that is, 1994). Possible negative feelings because of their invitation or participation, or both, in the prospect study may then cause a decrease in the attendance rate for breast cancer screening. Although this is not expected, attendance rates for screening in these women will be examined again in the future.

In most countries privacy regulations make it impossible to transfer names and addresses to others. In this study, names were transferred only after permission of the women themselves. The attendance rate for screening in this random sample of Utrecht women was $53 \%$. This is the attendance rate after a first call. All women who did not respond to their first invitation were invited again soon after and the attendance rate usually increased to approximately $60 \%$. Attendance rates of women living in cities in The Netherlands tend to be somewhat lower than rates in women living in the country. Attendance rates for the total female population in Utrecht, after their first call for a screening examination, in the years 1989, 1990, and 1991 respectively were $53 \%, 54 \%$, and $54 \%$. The present sample seems to be a representative sample in terms of overall attendance rates.

By January 1993, all women who still had not attended for a screening examination after a reminder were invited again. The attendance rate for screening, including screening visits after a second call, was $61 \%$ in both the prospect and control groups.

Some $58 \%$ of women (569 of 984 ) who came for a screening examination decided to participate in the additional prospect study. This study took one hour at home for filling out questionnaires and about half an hour extra at the screening centre. Also a blood sample was taken. This was known to the women before they made the decision to participate. Also it was strongly emphasised to these women that screening for breast cancer was in no way related to the prospect study, and that they were free to choose to participate in either one or both.

For the management of the prospect study, close cooperation with the screening unit was necessary. Only in this way was it possible to schedule prospect interviews jointly with screening examinations so that participating women only had to make one visit to the screening centre.

The participation rate in the prospect study was $31 \%$ (577 of 1863). This percentage is satisfactory, considering the age distribution of the invited population and the burden of the study (time consuming and taking blood samples). The rate will rise in the future for EPIC, since in The Netherlands women over age 69 years will not be invited. Also special press campaigns will possibly increase participation.

This study shows that inviting women for a prospective study additional to a screening examination does not deter them from attending screening, provided that proper invitation procedures are executed.

With thanks to the Stichting Vroege Opsporing Borstkanker Midden Nederland and the collaborators of Preventicon fo making this study possible; and to C A M Blank, J C Heykoop W J Schaafsma, P Strubbe, P Witjens, and R F Valeeva fo collecting the data. Financial support was given by the Commission of the European Communities (WHO/Agreemen AEP/90/05), WVC (91-106), and LK Research Fonds (36.91).

1 Waard de F, Collette HJA, Rombach JJ, Baanders-van Halewijn EA, Honing C. The DOM project for the early Halewijn EA, Honing C. The DOM project for the early
detection of breast cancer Utrecht, The Netherlands. detection of breast cancer
Chron Dis 1984;37:1-44.

2 Hendriks JHCL. Population screening for breast cancer by means of mammography in Nijmegen 1975-1980. Thesis, Nijmegen University, 1982 .

3 Collette HJA, Day NE, Rombach JJ, Waard de F. Evaluation of screening for breast cancer in a non-randomised study (the DOM-project) by means of a case-control study. Lancet 1984;i:1224-6.

4 Verbeek ALM, Hendriks JHCL, Holland R, Mravunac M, Sturmans F, Day NE. Reduction of breast cancer mortality through mass screening with modern mammor tality through mass screening with modern mammography. First results of
Lancet $1984 ; \mathrm{i}: 1222-4$.

5 Shapiro S, Venet W, Strax Ph, Venet L, Roeser R. Ten-tofourteen-year effect of screening on breast cancer morfourteen-year effect of screening on breast
tality. $\mathcal{F}$ Natl Cancer Inst 1982;69:349-55.

6 Tabar L, Fagerberg CJG, Gad A, et al. Reduction in mortality from breast cancer after mass screening with mammography. Lancet 1985; i:829-32.

7 UK Trial of early detection of breast cancer group. First results on mortality reduction in the U.K. Trial of early detection of breast cancer. Lancet 1988;ii:411-6.

8 Day NE, Williams DRR, Khaw KT. Breast cancer screening programmes: the development of a monitoring and evaluation system. $B r \not ु$ Cancer 1989;59:954-8.

9 Peeters PHM, Verbeek ALM, Hendriks JHCL, Bon van $\mathrm{MJH}$. Screening for breast cancer in Nijmegen. Report of 6 screening rounds, 1975-1986. Int $f$ Cancer 1989;43:226-30.

10 Duane B. Women's health research expected to remain a priority. News. I Natl Cancer Inst 1992;84:1776-7.

11 Riboli E. Nutrition and cancer: background and rationale of the European Prospective Investigation into Cancer and the European Prospective Investigation into

12 Koning de HJ, Ineveld BM, Oortmarssen van GJ, et al. Breast cancer screening and cost-effectiveness; policy alternatives, quality of life considerations and the possible impact of uncertain factors. Int $\mathcal{f}$ Cancer 1991;49:531-7. 